\title{
The GFRP profiles as stay-in-place formwork
}

\author{
Kinga Brózda $^{1, *}$, Jacek Selejdak ${ }^{1}$, and Peter Koteš ${ }^{2}$ \\ ${ }^{1}$ Czestochowa University of Technology, The Faculty of Civil Engineering, Akademicka 3, 42-200 \\ Czestochowa, Poland \\ ${ }^{2}$ University of Žilina, Civil Engineering Faculty, Univerzitná 8215/1, 01026 Žilina, Slovakia
}

\begin{abstract}
The GFRP (Glass Fibre Reinforced Polymers) materials are characterized by good mechanical properties and very high corrosion resistance. Currently the GFRP profiles in the form of modular structural elements are used as so called decking systems. However, the last researches concern the possibility of using the modular FRP profiles as a stay-in-place (SIP) formwork. In this article the conception of the shape and cross-sectional dimensions selection of the FRP profile was attempted. The conception applies to the prototype of the GFRP profile, which is able to use as a self-supporting formwork in composite slab in building structures on floors or as the deck in composite bridge structures. On the basis of theoretical and practical studies available in the literature, the theoretical evaluation of the composite element were done.
\end{abstract}

\section{Introduction}

The ever-deteriorating infrastructure creates the necessity for renovation and everincreasing demand for the replacement of existing building and engineering structures (or their structural parts). The repairs and renovations are more necessary especially if the construction is exposed to difficult environmental factors. Improving the durability of these structures may turn out better in the economic aspects, because a reduction in life-cycle cost and a decrease in frequency of necessary repairs and replacements [1].

The effective manner to increase the durability of buildings and engineering structures may be the utilization of the Fibre Reinforced Polymers (FRP) composites [1-4]. The scope of use of FRPs in the civil engineering industry is very wide. In existing constructions, it includes a fairly common use of the FRP elements in the form of thin sheets and laminates, which are bonded externally on the concrete surface [1]. However, another trend in the use of the FRPs in the implementation of new constructions are pultruded sections such as: bars and tendons, structural profiles, plates and gratings which can be externally bonded or positioned near surface as internal reinforcement [2].

The FRP materials are characterized by excellent physical and mechanical properties, including low self-weight, high tensile strength and very good resistance to corrosion. The unique properties of the FRPs are related to the structure of these advanced polymer composites. These are hybrid materials, which consist of two main components: the fibre (reinforcement) and the polymer (matrix) [2, 5-7]. The properties of the FRPs, especially

*Corresponding author: kbrozda@bud.pcz.pl 
resistance to electrochemical corrosion suggest their suitability for application into the building and engineering structures exposed to the action of the unfavourable environmental conditions [1].

\section{The stay-in-place FRP formwork}

All of these characteristics make the FRPs particularly well suited for the hybrid structural systems applications. Especially the implementation of the FRPs for structurally integrated stay-in-place (SIP) formwork appears to be very useful. The SIP formwork is a forming system that is permanently integrated with concrete and functions as the self-supporting formwork during construction. It is designed to act as a support during concreting and as a reinforcement in an expandable concrete zone when the concrete is cured [8-11]. The FRP SIP formwork can be exposed to aggressive environmental factors without significantly impact on the service life of the structure [2]. This hybrid system enhances the benefits of the FRP and concrete, while simplifying the implementation process and reducing the duration of construction [1].

Most currently available types of the FRP SIP formwork are adhesively bonded, pultruded shapes. These profiles usually are made from vinylester polymer and E-glass fiber. High quality of pultruded shapes is provided by specified standard manufacturing procedures [1]. Pultrusion is a continuous method of the FRP shapes production, indicated for constant cross-sections. This method ensures the suitable merging between resin matrix and fiber reinforcement, and receives the appropriate material properties by total impregnation of the fibers and high curing [12]. The disadvantage of this method is the high initial cost i.e. expensive tooling for pultrusion. Therefore, the manufacturing of most FRP forms are limited to typical structural shapes. The geometric parameters of some structural shapes can be modified (for example thicknesses and depths). However, the geometry of many pultruded shapes is fixed by the manufacturer [1].

\subsection{The conception of the SIP FRP formwork system}

The primary objective of the analysis is to determine the shape of structural profile which will be the main part of the stay-in-place formwork system. During analysis the loadcarrying capacity and the related maximum load force were taken into consideration. The results of research allow to determine the most effective cross-section of modular profile, which ensures the possibly highest quality of the bonding between GFRP formwork and concrete.

The FRP SIP formwork shown in the Fig. 1 [7, 8] is an example of a SIP formwork system which is based on hollow box sections. This system consists of the modular structural GFRP profiles, which can be connected with each other by special grooves and thus act as a self-supporting formwork for RC (reinforced concrete) slab. In this solution the load-carrying capacity highly depends on quality of the bonding between GFRP formwork and concrete.

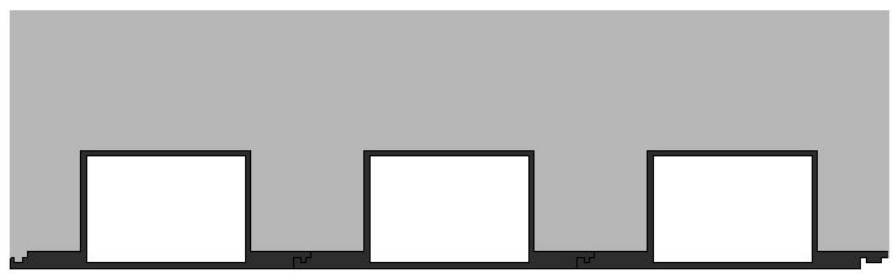

Fig. 1. The cross-section of the modular GFRP SIP formwork [9]. 


\subsection{The creation of the new trapezoidal-shaped section of FRP formwork}

Based on the SIP formwork system shown in Fig. 1, the attempt to develop the modular structural profile by modifying the box-shape to the trapezoidal was made (Fig. 2). This shape modifications can increase the bonding between FRP formwork and concrete and consequently provides more effective composite action. In addition, the appropriate surface treatment (e.g. sand-blast of FRP surface) can be carried out to increase the bonding between FRP and concrete. Using analytical calculations the theoretical analysis of the composite element was done.
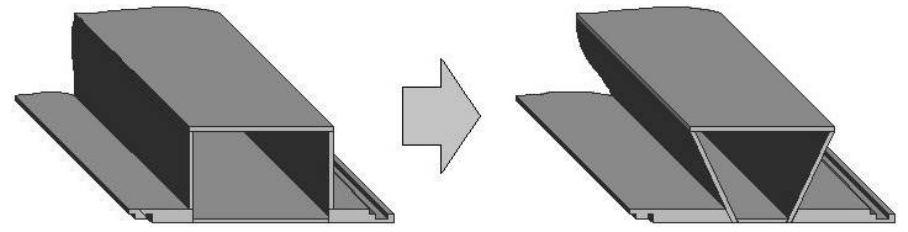

Fig. 2. The schema of the modified modular GFRP SIP formwork.

\section{The theoretical analysis}

\subsection{The assumed computational model}

The beam consisting of two layers was investigated: reinforced concrete slab of height $h_{\mathrm{f}}$ on the top and two GFRP girders on the bottom (Fig. 3). The GFRP girders are connected to each other mechanically with special grooves, so as to ensure adequate support of the casting concrete. The trapezoidal-shaped part of the profile provides additional mechanical anchorage with the cured concrete.

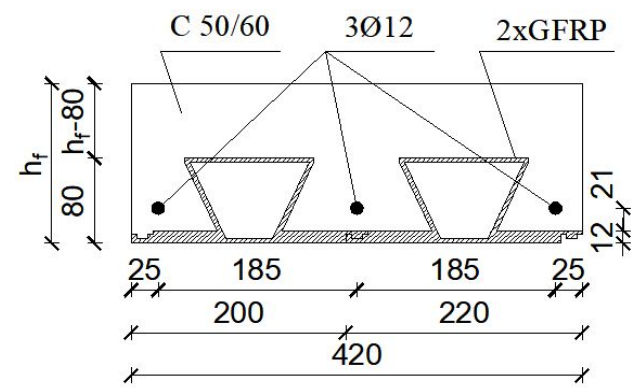

Fig. 3. The cross-section of composite SIP formwork system.

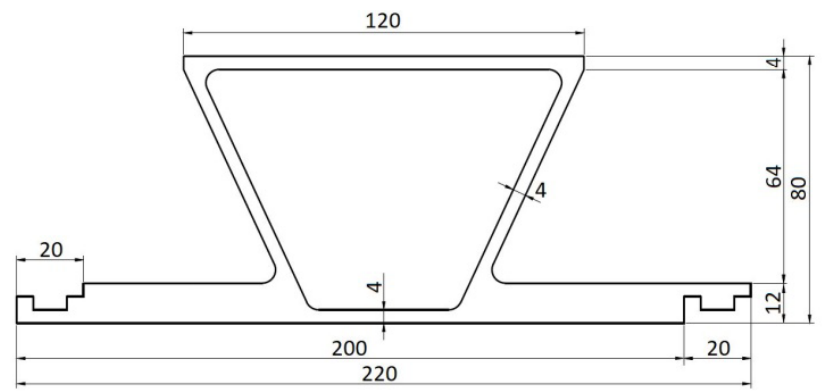

Fig. 4. The cross-section of composite SIP formwork system. 
The general dimensions of this SIP formwork cross-section are shown in Fig. 4. The total length of the beam was assumed as $3,500 \mathrm{~mm}$ and the width as $420 \mathrm{~mm}$. The material properties of the GFRP formwork were established as: the characteristic tensile strength $f_{\mathrm{tk}}=200 \mathrm{MPa}$ (approx. $29,103 \mathrm{psi}$ ), the modulus of elasticity $E_{\mathrm{f}}=25 \cdot 10^{3} \mathrm{MPa}$ (approx. $3625 \cdot 10^{3} \mathrm{psi}$ ), the density $\gamma_{\mathrm{f}}=1.835 \mathrm{~kg} / \mathrm{m}^{3}$ (approx. $112.4 \mathrm{lb} / \mathrm{ft}^{3}$ ). In the analysis the normal weight of concrete $\mathrm{C} 50 / 60$ was used: the characteristic compressive strength $f_{\mathrm{ck}}=50 \mathrm{MPa}$ (approx. $7250 \mathrm{psi}$ ). The steel grade B500A of the additional reinforcement placed above the connecting area was used: the characteristic tensile strength $f_{\mathrm{yk}}=500 \mathrm{MPa}$ (approx. $72,500 \mathrm{psi}$ ), the modulus of elasticity $E_{\mathrm{s}}=200 \cdot 10^{3} \mathrm{MPa}$ (approx. $29 \cdot 10^{6} \mathrm{psi}$ ). The diameter of reinforcing bars was $\Phi=12 \mathrm{~mm}$.

The calculation was done according to the same static schema (Fig. 5) as the original one [9].

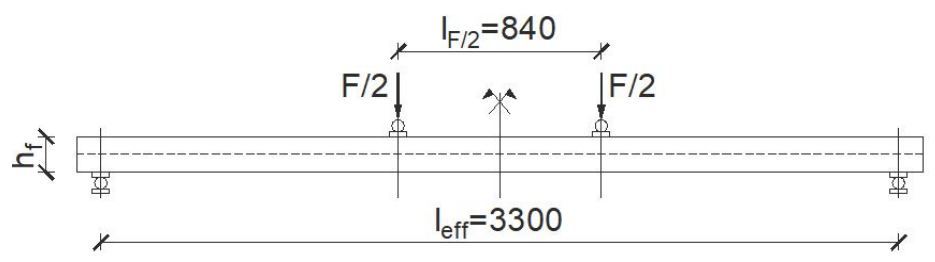

Fig. 5. The static schema of composite structure (GFRP formwork + RC).

\subsection{The calculation method}

In the theoretical investigation the perfect bonding between GFRP and concrete was considered. For the calculations it was assumed that strain over the section height changes linearly. The load-carrying capacity $M_{\mathrm{Rd}}$ depending on the height $h_{\mathrm{f}}$ of concrete slab was investigated. All calculations were done according to the standard [13, 14]. The loadcarrying capacity was calculated using the formula

$$
M_{\mathrm{Rd}}=\sum F_{\mathrm{f}, \mathrm{i}} \cdot d_{1, \mathrm{i}}+\sum F_{\mathrm{s} 1, \mathrm{j}} \cdot d_{1 . \mathrm{s} 1, \mathrm{j}}-F_{\mathrm{c}} \cdot 0.4 \cdot x
$$

where the symbol $F_{\mathrm{f}, \mathrm{i}}$ are the forces acting on individual areas of the GFRP profile and $F_{\mathrm{s} 1, \mathrm{j}}$ are the forces in reinforcement as shown in the Fig. 5. The $F_{\mathrm{c}}$ is the force in the compressed part of concrete, $x$ represents the compression zone height, $d_{1, \mathrm{i}}$ are the effective heights of individual parts of the GFRP profile and $d_{1, \mathrm{~s} 1, \mathrm{j}}$ are the effective heights of single bars. The values of other parameters were calculated according to the equations (2-6).

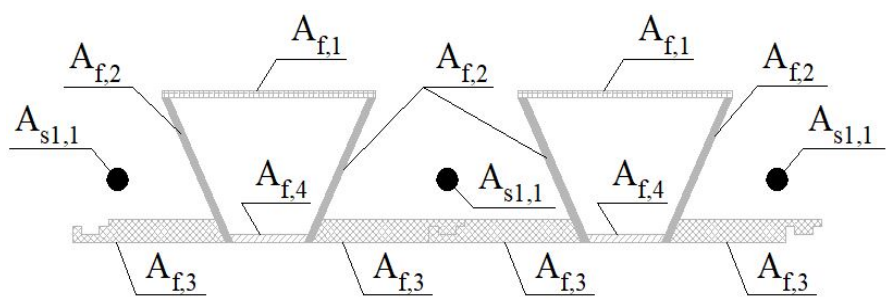

Fig. 6. The schema of individual areas of the GFRP cross-section.

$$
\begin{gathered}
F_{\mathrm{f}, \mathrm{i}}=\varepsilon_{\mathrm{f}, \mathrm{i}} \cdot E_{\mathrm{f}} \cdot A_{\mathrm{f}, \mathrm{i}} \\
F_{\mathrm{s} 1, \mathrm{j}}=\varepsilon_{\mathrm{s} 1, \mathrm{j}} \cdot E_{\mathrm{s}} \cdot A_{\mathrm{s} 1, \mathrm{j}} \\
F_{\mathrm{c}}=0.8 \cdot \eta \cdot f_{\mathrm{cd}} \cdot x \cdot b
\end{gathered}
$$




$$
\begin{gathered}
\varepsilon_{\mathrm{f}, \mathrm{i}}=\varepsilon_{\mathrm{cu}, 3} \cdot\left(d_{1, \mathrm{i}}-x\right) \cdot x^{-1} \\
\varepsilon_{\mathrm{s} 1, \mathrm{j}}=\varepsilon_{\mathrm{cu}, 3} \cdot\left(d_{1 . \mathrm{s} 1, \mathrm{j}}-x\right) \cdot x^{-1}
\end{gathered}
$$

The symbol $\varepsilon_{\mathrm{f}, \mathrm{i}}$ are the stains acting on individual parts of the GFRP profile (Fig. 6), $\varepsilon_{\mathrm{s} 1 \mathrm{j}}$ on reinforcement and $\varepsilon_{\mathrm{cu}, 3}$ is ultimate compressive strain in concrete. The $E_{\mathrm{f}}$ is the modulus of elasticity of the GFRP and $E_{\mathrm{s}}$ of the reinforcement. The areas of individual parts of GFRP are marked as $A_{\mathrm{f}, \mathrm{i}}$ and of reinforcement as $A_{\mathrm{s} 1 \mathrm{j}, \mathrm{j}}$. The symbol $\eta$ is the ratio for the physical description of the stress-strain diagram for concrete. The width of composite girder is marked as $b$ and $f_{\text {cd }}$ is the design value of concrete compressive strength.

The maximum force $F_{\max }$ was also investigated. The force was calculated by using formula (7).

$$
F_{\max }=4 \cdot M_{\mathrm{Rd}} \cdot\left(l_{\mathrm{eff}}-l_{\mathrm{F} / 2}\right)^{-1}
$$

The symbol $l_{\text {eff }}$ is the length of theoretical span and $l_{\mathrm{F} / 2}$ is the distance between loading forces equal to $2 \cdot F_{\max }$.

\subsection{The results of the computational analysis}

The results which are obtained from the computational analysis of the trapezoidal-shaped profile were compared with results of the original shape [9]. The obtained results of the load-carrying capacity $M_{\mathrm{Rd}}$ were shown in Table 1 .

Table 1. The results of the load-carrying capacity analysis.

\begin{tabular}{|c|c|c|}
\hline $\begin{array}{c}\text { Height } \boldsymbol{h}_{\mathbf{f}} \text { of } \\
\text { the slab } \\
{[\mathbf{m m}]}\end{array}$ & $\begin{array}{c}\text { Load-carrying capacity } \boldsymbol{M}_{\mathbf{R d}} \text { of } \\
\text { the trapezoidal-shaped profile } \\
{[\mathbf{k N} \cdot \mathbf{m}]}\end{array}$ & $\begin{array}{c}\text { Load-carrying capacity } \boldsymbol{M}_{\mathbf{R d}} \text { of } \\
\text { the box-shaped profile [9] } \\
{[\mathbf{k N} \cdot \mathbf{m}]}\end{array}$ \\
\hline 120 & 50.38 & 47.86 \\
\hline 130 & 58.18 & 55.32 \\
\hline 140 & 66.71 & 63.47 \\
\hline 150 & 75.91 & 72.26 \\
\hline 160 & 85.74 & 81.65 \\
\hline 170 & 96.18 & 91.61 \\
\hline 180 & 107.19 & 102.12 \\
\hline 190 & 118.77 & 113.16 \\
\hline 200 & 130.88 & 124.70 \\
\hline
\end{tabular}

The analytical calculations proved that by modification of the hollow box shape to a trapezoidal one has contributed to the increase of the load-carrying capacity by $4.95-5.27 \%$. It means that the modification of the section has resulted in the possibility of increasing the maximum permissible load. There is also a possibility to reduce the height of the concrete slab, thereby reducing the material consumption.

In addition, based on the results of obtained values of the load-carrying capacity, the maximum load forces $F_{\max }$ were calculated and compared with the results of the original shape [9]. The comparison is summarized in Table 2. 
Table 2. The results of the maximum load force analysis.

\begin{tabular}{|c|c|c|}
\hline $\begin{array}{c}\text { Height } \boldsymbol{h}_{\mathbf{f}} \text { of } \\
\text { the slab } \\
{[\mathbf{m m}]}\end{array}$ & $\begin{array}{c}\text { Maximum load force } \boldsymbol{F}_{\text {max }} \text { of } \\
\text { the trapezoidal-shaped profile } \\
{[\mathbf{k N}]}\end{array}$ & $\begin{array}{c}\text { Maximum load force } \boldsymbol{F}_{\text {max }} \text { of } \\
\text { the box-shaped profile [9] } \\
{[\mathbf{k N}]}\end{array}$ \\
\hline 120 & 81.92 & 77.82 \\
\hline 130 & 94.60 & 89.96 \\
\hline 140 & 108.47 & 103.21 \\
\hline 150 & 123.43 & 117.50 \\
\hline 160 & 139.41 & 132.77 \\
\hline 170 & 156.39 & 148.96 \\
\hline 180 & 174.29 & 166.05 \\
\hline 190 & 193.12 & 184.00 \\
\hline 200 & 212.81 & 202.77 \\
\hline
\end{tabular}

\section{Conclusion}

In this paper, the authors have proposed the lightweight and easy to install GFRP SIP formwork for slabs. The formwork system is based on hollow trapezoidal-shaped section. The analytical calculations of the composite element (GFRP formwork + RC slab) were done. The load-carrying capacity depending on the height of concrete slab and the associated maximum load force were investigated. The results were compared with the prototype box-shaped section [9].

Through the computational analysis, the purposefulness of modifying the shape of the cross-section of the modular profile has been proven. Moreover, the load-carrying capacity increasing by shape modification allows to reduce the consumption of concrete, which is associated with a reduction in the dead weight of the structure. The results will be used in the analytical tests and numerical model. The further experimental investigation of the bonding between GFRP and concrete is necessary. It is expected that modifying the boxshape to the trapezoidal one can increase the bonding, because of the supplementary mechanical interlock due to the trapezoidal-shaped section. The additional GFRP surface treatment like rougher surface (lugs) or sand-blast could also improve the bonding between the two materials. Due to the better bonding, the higher value of the load-carrying capacity can be achieved.

The use of FRPs in SIP formwork systems reduces the self-weight of the formed structure and increase economic efficiency. Moreover, the modular GFRP profile provides an additional corrosive protection of steel reinforcement. Due to the anticorrosive properties, the use of this GFRP SIP formwork system is mainly intended for structures exposed to an aggressive environment, providing a long failure-free service life with little maintenance.

\section{References}

1. M. S. Nelson, A. Z. Fam, J. P. Busel, C. E. Bakis, A. Nanni, L. C. Bank, M. Henderson, J. Hanus, Aci Structural Journal, 111, 1069-1080 (2014)

2. R. Goyal, A. Mukherjee, S. Goyal, Cons. and Build. Mat., 113, 741-751 (2016) 
3. R. Goyal, A. Mukherjee, S. Goyal, Steel and Comp. Struct., 20(3), 671-692 (2016)

4. R. Goyal, S. Goyal, A. Mukherjee, Current Sci., 113(2), 245-252 (2017)

5. L. C. Hollaway, https://doi.org/10.1533/9780857098641.4.582

6. K. Brózda, J. Selejdak, P. Koteš, Proc. Eng., 192, 64-68 (2016)

7. K. Brózda, M. Major, J. Selejdak, 23th Internat. Conf. EM2017, 218-221 (2017)

8. P. Koteš, J. Vičan, 3th Internat. fib Congress incorp. the PCI Annual Convention and Bridge Conf., 1(6), 11 (2010)

9. P. Koteš, J. Vičan, 7th Internat. Conf. on FRP Comp. in Civil Eng., 198-204 (2014)

10. X. Gai, A. Darby, T. Ibell, M. Evernden, 10th Internat. Symp. on FRP Reinforcement for Concrete Structures, 971-988 (2011)

11. X. Gai, A. Darby, T. Ibell, M. Evernden, Cons. and Build. Mat., 49, 1013-1023 (2013)

12. K. Brózda, J. Selejdak, Prod. Eng. Archives, 12, 2-4 (2016)

13. EN 1991-1-1:2002

14. EN 1992-1-1:2004 